\title{
Effects of Long-Term Intravenous Administration of Adrenomedullin (AM) Plus hANP Therapy in Acute Decompensated Heart Failure
}

\author{
A Pilot Study
}

\author{
Toshio Nishikimi; Tsuyoshi Karasawa*; Chikako Inaba; Kimihiko Ishimura; \\ Kazuyoshi Tadokoro; Shogo Koshikawa; Fumiki Yoshihara**; \\ Noritoshi Nagaya ${ }^{\dagger}$; Hideaki Sakio*; Kenji Kangawa†; Hiroaki Matsuoka
}

\begin{abstract}
Background: It was reported previously that $30 \mathrm{~min}$ administration of adrenomedullin (AM) improves hemodynamics in chronic stable heart failure patients. The present study was designed to examine whether long-term AM+human atrial natriuretic peptide (hANP) administration can be used as a therapeutic drug in patients with acute decompensated heart failure (ADHF) in clinical setting.

Methods and Results: Seven acute heart failure patients (74 \pm 5 years) with dyspnea and pulmonary congestion were studied. AM $\left(0.02 \mu \mathrm{g} \cdot \mathrm{kg}^{-1} \cdot \mathrm{min}^{-1}\right)+\mathrm{hANP}\left(0.05 \mu \mathrm{g} \cdot \mathrm{kg}^{-1} \cdot \mathrm{min}^{-1}\right)$ was infused for $12 \mathrm{~h}$ and then hANP $\left(0.05 \mu \mathrm{g} \cdot \mathrm{kg}^{-1} \cdot \mathrm{min}^{-1}\right)$ was infused for $12 \mathrm{~h}$. Hemodynamic, renal, hormonal and oxidative stress responses were evaluated. AM+hANP significantly reduced mean arterial pressure, pulmonary arterial pressure and systemic and pulmonary vascular resistance without changing heart rate, and increased cardiac output for most time-points compared with those at baseline. In addition, AM $+\mathrm{hANP}$ reduced aldosterone, brain natriuretic peptide and free-radical metabolites compared with those at baseline (all $\mathrm{P}<0.05)$. AM+hANP increased urine volume and $\mathrm{UNaV}$ compared with baseline data.

Conclusions: In this small, pilot trial, AM + hANP therapy had beneficial hemodynamic and hormonal effects in ADHF. Intravenous infusion of AM with hANP could be used as a therapeutic drug in ADHF. These data are preliminary and require confirmation in a larger clinical study. (Circ J 2009; 73: 892-898)
\end{abstract}

Key Words: Acute decompensated heart failure; Adrenomedullin; Atrial natriuretic peptide; Brain natriuretic peptide; Oxidative stress

A drenomedullin (AM), a strong vasodilatory peptide, was originally isolated from human pheochromocytoma! Infusion of AM causes vasodilatation, diuresis and natriuresis in normal animals? AM also increases cardiac output and left ventricular contractility in vivo and exerts a direct inotropic effect in vitro? We and others have shown that plasma AM levels are increased in patients with congestive heart failure.,5 Tissue levels of the AM peptide and mRNA have also been shown to be increased in the heart, kidney and lungs of rats with congestive heart failure6 These findings suggest that AM may play a role in the regulation of volume and pressure homeostasis in congestive heart failure as a paracrine and/or autocrine factor, and as a circulating hormone. In addition, we reported previously beneficial hemodynamic and renal

(Received May 19, 2008; revised manuscript received December 11, 2008; accepted December 17, 2008; released online April 2, 2009)

Department of Hypertension and Cardiorenal Medicine, *Department of Intensive and Critical Care Medicine, Dokkyo Medical University, Mibu, **Department of Medicine, National Cardiovascular Center and ${ }^{\dagger}$ Research Institute National Cardiovascular Center, Suita, Japan Mailing address: Toshio Nishikimi, MD, Department of Hypertension and Cardiorenal Medicine, Dokkyo University School of Medicine, Mibu 321-0293, Japan. E-mail: nishikim@ dokkyomed.ac.jp All rights are reserved to the Japanese Circulation Society. For permissions, please e-mail: cj@j-circ.or.jp effects of AM infusion in animals with congestive heart failure? In humans, systemically administered AM has been shown to decrease mean arterial pressure (MAP) significantly in healthy subjects without any adverse effects? These findings raise the possibility that intravenous infusion of AM may also be beneficial in human subjects with heart failure. Indeed, we and other investigators demonstrated previously that short-term infusion of AM increased the cardiac index (CI) and decreased mean pulmonary arterial pressure (mPA) only in patients with chronic stable heart failure9,10 In comparison with human atrial natriuretic peptide (hANP), AM is more potent in decreasing vascular resistance and enhancing cardiac output, and less potent in diuresis and natriuresis $!^{1}$ The infusion of hANP is currently used as a treatment for acute decompensated heart failure (ADHF) in Japan; however, some of the patients with ADHF are resistant to hANP monotherapy. Taken together, these results suggest that AM+ANP therapy may be used as a therapeutic drug in ADHF. However, it is not known whether long-term AM+ANP infusion in ADHF is beneficial or not.

Therefore, our aim in the present study was thus to investigate if long-term AM+ANP infusion therapy was effective in terms of hemodynamics, renal function and hormone levels in patients with ADHF in a real clinical setting. 


\section{Methods}

The present study was approved by the ethics committee of the Dokkyo Medical University, and all patients gave written informed consent.

\section{Study Subjects}

Seven patients with ADHF who were admitted to our hospital with a prime complaint of dyspnea were studied. Chest X-rays in all patients showed cardiomegaly with pulmonary congestion. After written informed consent was obtained, baseline blood tests and echocardiography were performed. Patients with one of the following conditions were excluded: (1) chronic renal impairment (serum creatinine level $2.0 \mathrm{mg} / \mathrm{dl}$ ); (2) systolic blood pressure $<100 \mathrm{mmHg}$; or (3) the presence of aortic stenosis or mitral stenosis. The baseline clinical characteristics and hemodynamics in the present study are shown in Table.

\section{Preparation of Human AM}

Human AM was obtained from Peptide Institute Inc, Osaka, Japan. The homogeneity of human AM was confirmed using reverse-phase, high-performance liquid chromatography and amino acid analysis. AM was dissolved in saline with $4 \%$ D-mannitol and sterilized through a $0.22-\mu \mathrm{m}$ filter (Millipore Co, Billerica, MA, USA). Then, randomly selected vials were submitted for sterility and pyrogen testing, as reported previously 10 The chemical nature and content of the human AM in the vials were verified using high-performance liquid chromatography and radioimmunoassay.

\section{Study Protocol}

All patients were hospitalized in our intensive care unit. A 7.5-F Swan-Ganz catheter (TOO21H-7.5F, Baxter Co, Deerfild, IL, USA) was positioned in the pulmonary artery through a jugular vein. One 22-gauge cannula was inserted into a radial artery for hemodynamic measurements and blood sampling. Another 22-gauge cannula was inserted into a forearm vein for the infusion of $0.9 \%$ hANP, with or without AM. A bladder catheter was inserted for urine sampling. During an equilibration period of $60 \mathrm{~min}$, baseline hemodynamic, renal and blood samples for hormonal measurements were obtained. Then, AM $\left(0.02 \mu \mathrm{g} \cdot \mathrm{kg}^{-1}\right.$. $\left.\mathrm{min}^{-1}\right)+\mathrm{hANP}\left(0.05 \mu \mathrm{g} \cdot \mathrm{kg}^{-1} \cdot \mathrm{min}^{-1}\right)$ were administered intravenously at a rate of $0.5 \mathrm{ml} / \mathrm{min}$ for $12 \mathrm{~h}$, followed by
Table. Patient Characteristics

\begin{tabular}{lc}
\hline Age (years) & $74 \pm 5$ \\
M/F & $5 / 2$ \\
BMI (kg/m²) & $25.7 \pm 5.2$ \\
NYHA (III/IV) & $5 / 2$ \\
Cause of HF (IHD/valvular) & $4 / 3$ \\
BNP (pg/ml) & $1,350 \pm 1,187$ \\
Cre (mg/dl) & $1.0 \pm 0.5$ \\
Echocardiographic findings & \\
LVDd & $61 \pm 6$ \\
LVDs & $46 \pm 8$ \\
EF & $39 \pm 10$ \\
MR (II/III/IV) & $2 / 1 / 4$ \\
AR (III) & 1 \\
Baseline hemodynamic data & \\
MAP & $98 \pm 17$ \\
SVR & $1,699 \pm 529$ \\
CI & $2.54 \pm 0.80$ \\
HR & $73 \pm 14$ \\
mPA & $45 \pm 15$ \\
PAR & $370 \pm 252$ \\
PCWP & $27 \pm 9$ \\
\hline
\end{tabular}

BMI, body mass injdex; NYHA, New York Heart Association; HF, heart failure; MAP, mean arterial pressure; SVR, systemic vascular resistance; CI, cardiac index; HR, heart rate; $\mathrm{mPA}$, mean pulmonary arterial pressure; PAR, pulmonary arterial resistance; PCWP, pulmonary capillary wedge pressure.

12h of hANP $\left(0.05 \mu \mathrm{g} \cdot \mathrm{kg}^{-1} \cdot \mathrm{min}^{-1}\right)$ infusion (Figure 1). Hemodynamic parameters, including heart rate (HR), MAP, mPA, pulmonary capillary wedge pressure (PCWP) and cardiac output, were continuously monitored and measured at 60-min intervals during the protocol. Blood samples were taken before, $12 \mathrm{~h}$ after AM+hANP infusion and $12 \mathrm{~h}$ after hANP monotherapy. Urine samples were obtained every $60 \mathrm{~min}$. Urine volume, urinary sodium excretion, urinary potassium excretion, urinary cAMP and cGMP excretion were measured and calculated using standard formulas.

\section{Hormone and Oxidative Stress Marker Measurement}

Plasma total AM, mature AM, atrial natriuretic peptide (ANP) and brain natriuretic peptide (BNP) levels were measured using immunoradiometric assays with a specific kit for each marker (Shionogi Co, Ltd, Osaka, Japan) ${ }^{11}$ Plasma cyclic adenosine 3', 5'-monophosphate (cAMP), cyclic guanosine 3', 5'-monophosphate (cGMP), renin, aldosterone and norepinephrine (NE) were measured with commercially available kits! ${ }^{2}$ Reactive oxygen metabolite (d-ROM) was

\section{Study Protocol}

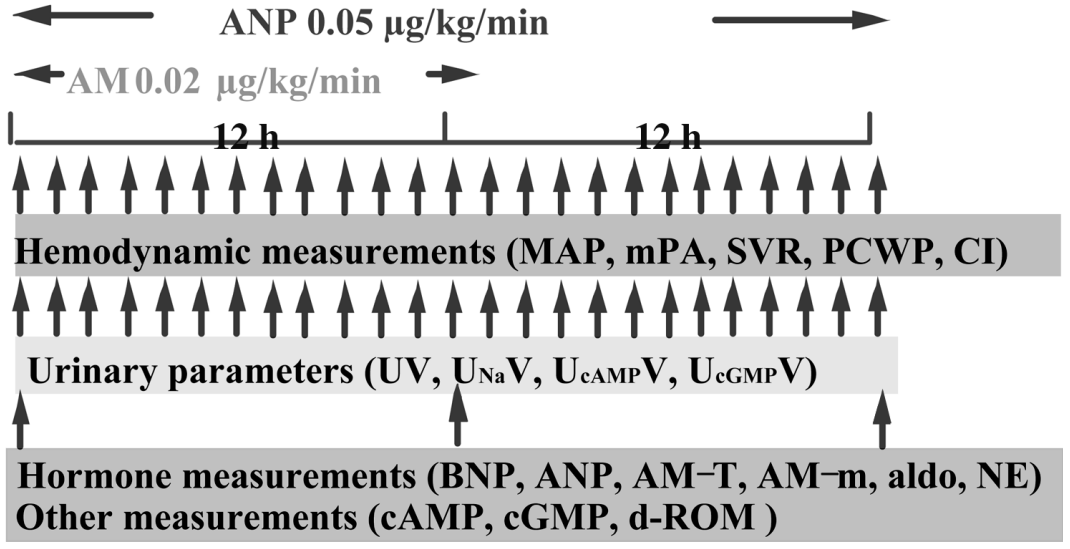

Figure 1. Study protocol. After a 60-min baseline period, AM $\left(0.02 \mu \mathrm{g} \cdot \mathrm{kg}^{-1} \cdot \mathrm{min}^{-1}\right)+$ hANP $\left(0.05 \mu \mathrm{g} \cdot \mathrm{kg}^{-1} \cdot \mathrm{min}^{-1}\right)$ was administered intravenously for $12 \mathrm{~h}$, followed by hANP $\left(0.05 \mu \mathrm{g} \cdot \mathrm{kg}^{-1} \cdot \mathrm{min}^{-1}\right)$ monotherapy for $12 \mathrm{~h}$. AM, adrenomedullin; AM-m, AM-mature; AM-T, AM-total; ANP, atrial natriuretic peptide; BNP, brain natriuretic peptide; cAMP, cyclic adenosine 3', 5'-monophosphate; CI, cardiac index; cGMP, cyclic guanosine 3', 5'monophosphate; d-ROM, reactive oxygen metabolite; hANP, human atrial natriuretic peptide; MAP, mean arterial pressure; mPA, mean pulmonary arterial pressure; $\mathrm{NE}$, norepinephrine; PCWP, pulmonary capillary wedge pressure; SVR, systemic vascular resistance. 
A

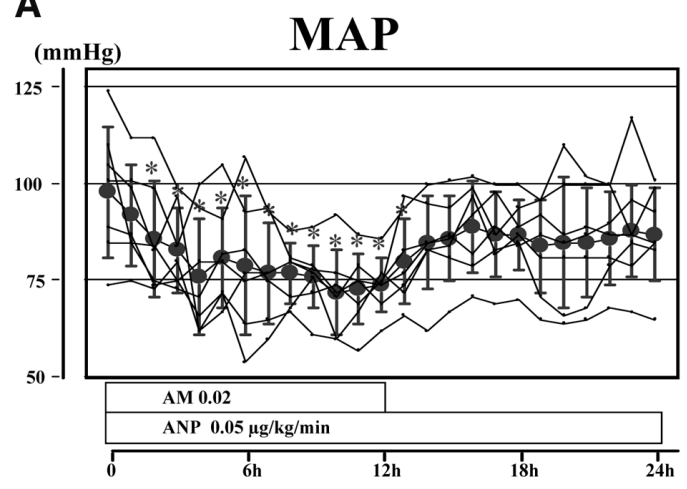

C

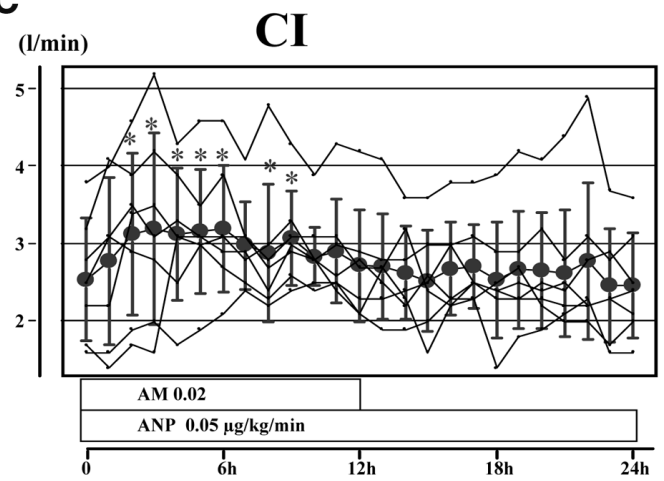

B

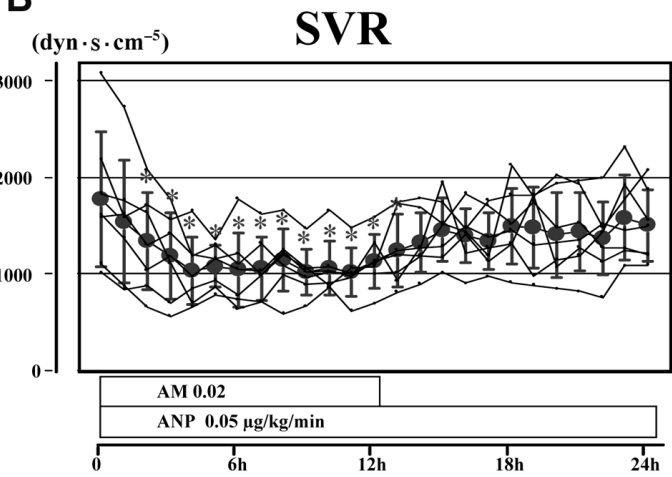

D

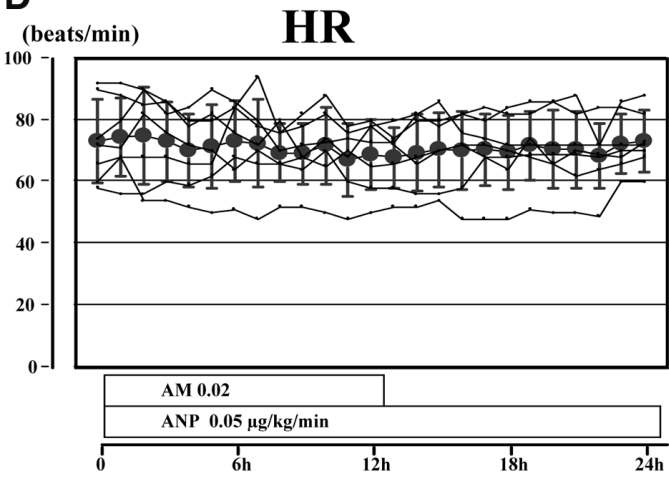

Figure 2. Systemic hemodynamic [(A) MAP, (B) SVR, (C) CI and (D) HR] changes during the infusion of AM+hANP and hANP therapy. Data are mean $\pm \mathrm{SD}$. ${ }^{*} \mathrm{P}<0.05$ vs value at time 0 . HR, heart rate. Other abbreviations see in Figure 1.

A

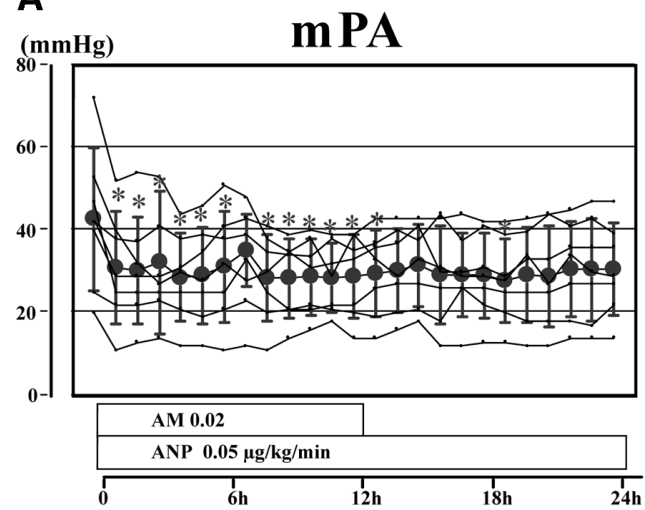

C

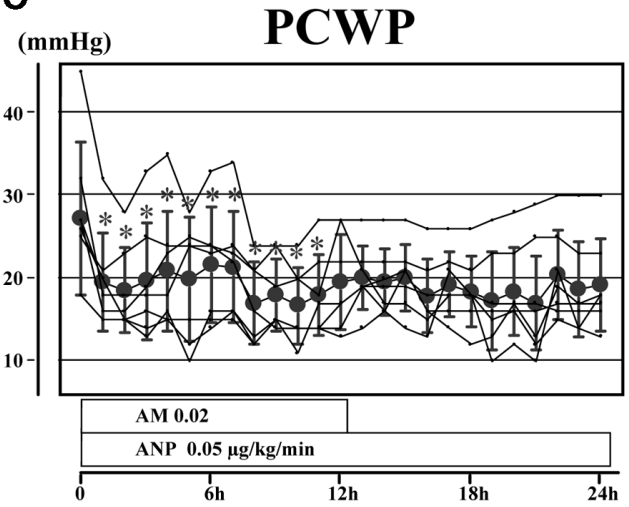

B

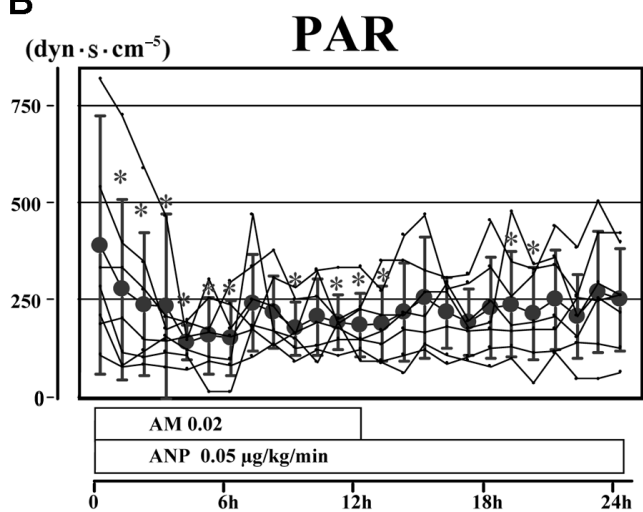

Figure 3. Pulmonary hemodynamic $[(\mathbf{A}) \mathrm{mPA},(\mathbf{B}) \mathrm{PAR}$ and $(\mathbf{C}) \mathrm{PCWP}]$ changes during the infusion of AM+hANP and hANP therapy. Data are mean $\pm \mathrm{SD}$. $* \mathrm{P}<0.05$ vs value at time 0 . PAR, pulmonary arterial resistance. Other abbreviations see in Figure 1. 
A
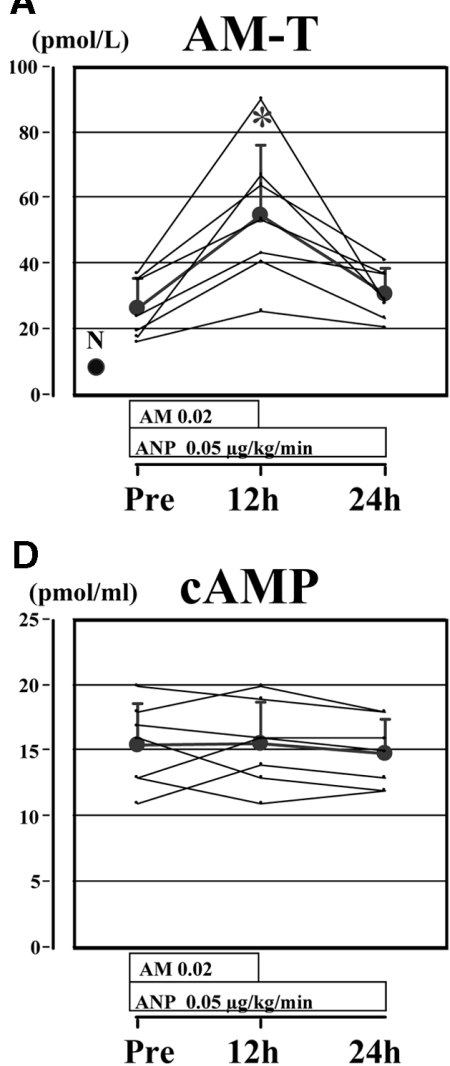

B

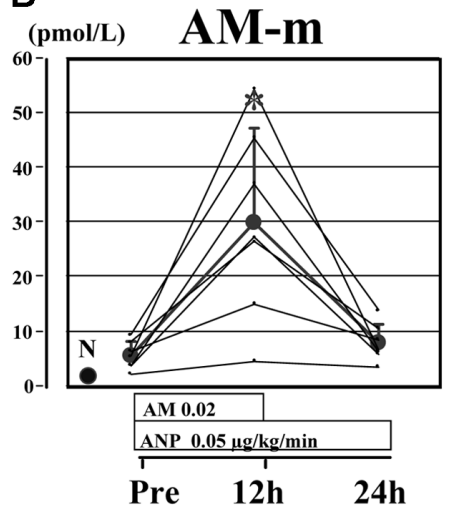

E

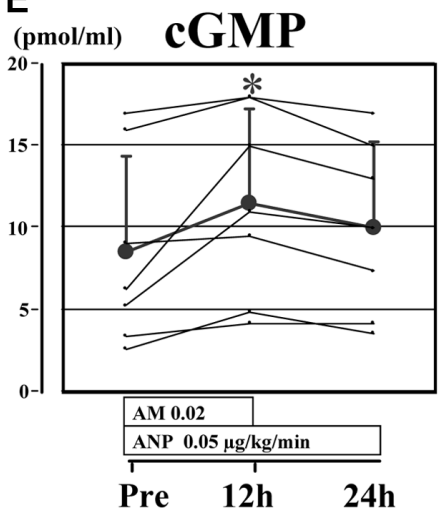

C

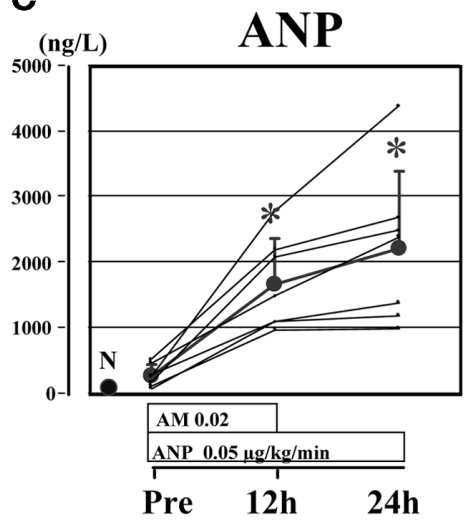

Figure 4. Hormonal [(A) AM-T, (B) AM-m, (C) ANP, (D) cAMP and (E) cGMP] changes during infusion of AM+hANP and hANP therapy. Data are mean \pm SD. $* \mathrm{P}<0.05$ vs value at time 0 . Abbreviations see in Figure 1.

measured using a commercially available kit (H\&D, s.r.l., Parma, Italy).

\section{Statistical Analysis}

All data were expressed as mean \pm SD unless otherwise indicated. Comparisons of the parameters between the baseline data and each time point were made using a paired Student's t-test. Log transformation was completed for plasma BNP and ANP levels. $\mathrm{P}<0.05$ was considered statistically significant.

\section{Results}

All subjects tolerated the present study protocol. No obvious side effects were observed in blood chemistry tests such as liver function, renal function, electrolytes or hemograms. The 2 of 7 patients had mild skin flushing in the body during the AM+hANP therapy. This disappeared soon after switching to ANP monotherapy.

\section{Hemodynamic Responses to AM and hANP}

The infusion of AM+hANP significantly decreased MAP, systemic vascular resistance (SVR), and increased CI (Figures $2 \mathbf{A}-\mathbf{C}$ ) at most of the time-point compared with the baseline levels, whereas there were no changes in HR (Figure 2D). Infusion of AM+hANP also significantly decreased mPA, pulmonary vascular resistance and PCWP at most time-points compared with the baseline values (Figures 3A-C).

\section{Hormonal and Oxidative Stress Responses to AM and hANP}

Baseline plasma total AM, mature AM and ANP were significantly elevated in patients with heart failure and were comparable with previous reports (Figures $\mathbf{4 A}-\mathbf{C}$ ). At the end of AM+hANP infusion, plasma total AM, mature AM and ANP increased about 2-fold, 6-fold and 6-fold, respectively. After switching to hANP monotherapy, plasma total $\mathrm{AM}$ and mature AM decreased to near baseline levels, whereas plasma ANP increased further (Figures 4A-C).

Infusion of AM+hANP significantly increased the plasma level of cGMP, which is a secondary messenger for ANP, $\mathrm{BNP}$ and nitric oxide (Figure 4E). Plasma levels of cAMP, one of the secondary messengers of AM, did not change significantly during the study period (Figure 4D).

The effects of infusion of AM+hANP on plasma BNP, aldosterone, NE, PRA, and d-ROM are shown in Figure 5. Infusion of AM+hANP significantly decreased plasma BNP and aldosterone levels (Figures 5A, B). In contrast, NE or PRA levels did not change (Figures 5C,D). Interestingly, the infusion of AM+hANP significantly decreased d-ROM levels, a marker of oxidative stress (Figure 5E).

\section{Renal Urinary Responses to AM and hANP}

Infusion of AM+hANP tended to increase urine volume, urinary sodium excretion and urinary cAMP excretion compared with the baseline level and these changes reached statistical significance at several points; however, there seemed to be no differences in these parameters between AM+hANP and hANP monotherapy. Whereas urinary cGMP excretion was significantly higher for almost entire period compared 
A

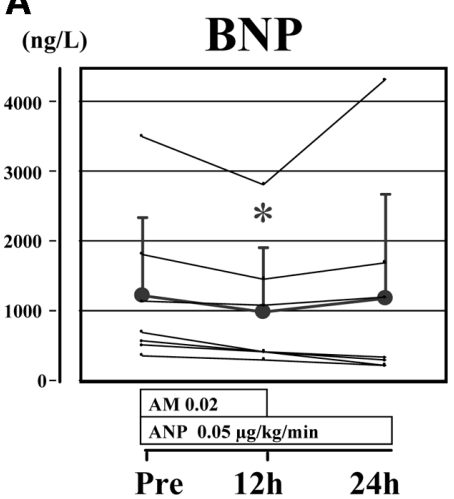

C

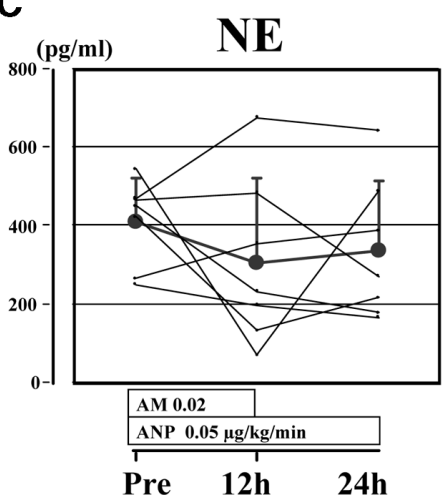

B

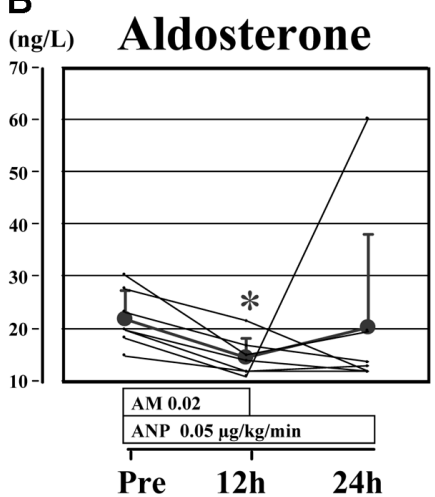

D

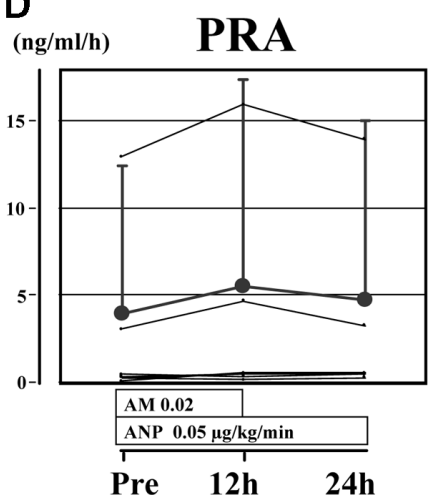

E

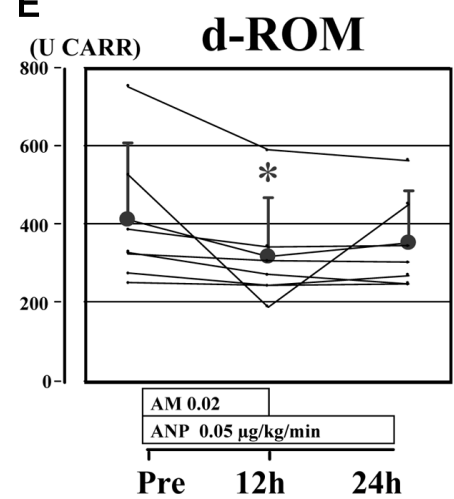

Figure 5. Hormonal [(A) BNP, (B) aldosterone, (C) NE and (D) PRA] and (E) oxidative stress marker (d-ROM) changes during the infusion of AM+hANP and hANP therapy. Data are mean $\pm \mathrm{SD}$. $* \mathrm{P}<0.05$ vs value at time 0 . Abbreviations see in Figure 1.

with the baseline level (data not shown).

\section{Discussion}

In our small pilot trial, the administration of combined AM+hANP in patients with ADHF was effective in reducing MAP, SVR, mPA, PAR, PCWP, BNP, aldosterone and d-ROM, and in increasing CI, UV, $\mathrm{UNaV}_{\mathrm{N}}, \mathrm{U}_{\mathrm{cAMPV}}$ and $\mathrm{U}_{\mathrm{cGMPV}}$. These results suggest that long-term $\mathrm{AM}+\mathrm{hANP}$ infusion may be an effective treatment for patients with ADHF in a real clinical setting due to the reduction of systemic and pulmonary vascular resistance, positive inotropic effects, inhibitory action of aldosterone secretion and oxidative stress production.

In the present study, AM+hANP therapy significantly decreased SVR, MAP, PAR and mPA without changing HR. Previous studies have demonstrated that AM directly dilated vascular smooth muscle cells in a cAMP-dependent manner! ${ }^{13}$ A further study also showed that AM dilates vessels via a cGMP cascade with the production of nitric oxide ${ }^{14,15}$ In the present study, plasma cAMP levels did not increase, maybe due to the low dose of AM $\left(0.02 \mu \mathrm{g} \cdot \mathrm{kg}^{-1}\right.$. $\mathrm{min}^{-1}$ ), because our previous studies showed that higher doses of AM $\left(0.05 \mu \mathrm{g} \cdot \mathrm{kg}^{-1} \cdot \mathrm{min}^{-1}\right)$ increased plasma cAMP levels in patients with chronic heart failure and pulmonary hypertension! 10,16 Thus, whether plasma cAMP increased or not appeared to depend on the dose of AM used. HR did not increase in the present study. Previous studies have demonstrated that AM induced an increase of HR! 10 This discrepancy of the results between two studies may be explained by the two reasons: (1) a low dose of AM $\left(0.02 \mu \mathrm{g} \cdot \mathrm{kg}^{-1} \cdot \mathrm{min}^{-1}\right)$ was used in the present study compared with the previous study $\left(0.05 \mu \mathrm{g} \cdot \mathrm{kg}^{-1} \cdot \mathrm{min}^{-1}\right)$; and (2) hANP was concominantly used in the present study. Because hANP is known to exert a sympathoinhibitory action in heart failure, AMinduced reflex-mediated sympathetic activation may be blunted. Thus, a combination of AM + hANP would aid HR stability through mutual effects! ${ }^{17}$

In the present study, AM+hANP therapy increased CI. Because AM+hANP therapy reduced SVR and PAR significantly, the observed increase of CI may be in part due to a reduction of afterload. In addition, several reports demonstrated that AM has positive inotropic effects. Szokodi et al reported that AM enhances cardiac contractility via cAMPindependent mechanisms, including a $\mathrm{Ca}^{2+}$ release from intracellular ryanodine- and thapsigargin-sensitive $\mathrm{Ca}^{2+}$ stores, activation of protein kinase $\mathrm{C}$ and $\mathrm{Ca}^{2+}$ influx through L-type $\mathrm{Ca}^{2+}$ channels ${ }^{18}$ In agreement with these findings, Nagaya et al demonstrated that intravenous AM enhances left ventricular myocardial contraction and improves left ventricular relaxation without increasing myocardial oxygen consumption in patients with left ventricular dysfunction. 19 Thus, positive inotropic effects from AM, not mediated via the cAMP/PKA pathway, may be useful in the treatment for ADHF.

Interestingly, AM+hANP therapy reduced BNP, aldosterone and d-ROM levels. The reduction of BNP is considered to be due to hemodynamic improvement, including reduction of SVR, PAR and PCWP 20 Interestingly, AM+ hANP therapy reduced plasma aldosterone levels. Previous studies demonstrated that AM inhibits aldosterone production induced by angiotensin II, potassium and $\mathrm{Ca}^{2+}$ ion- 
ophores in dispersed zona glomerulosa cells, ${ }^{2,3}$ In vivo, AM prevents increased plasma aldosterone levels induced through the infusion of angiotensin II, a sodium-deficient diet or bilateral nephrectomy 11,22 These findings suggest that AM may have a role in inhibiting aldosterone secretion from zona glomerulosa cells. In addition, intravenous infusion of AM reduced aldosterone levels in humans: ${ }^{10,11,16}$ Thus, it is possible that AM directly inhibits aldosterone secretion in heart failure. Several lines of evidence show that AM has antioxidative effects 2,3 A recent study has demonstrated that angiotensin II-induced reactive oxygen species production through the activation of NADPH oxidase was significantly attenuated by AM in a concentration-dependent manner.23 Increased oxidative stress plays a major role in the pathogenesis of heart failure 24,25 Thus, the inhibitory effects of AM on aldosterone secretion and production of reactive oxidative species may be useful in the treatment for heart failure.

$\mathrm{AM}+\mathrm{hANP}$ therapy appeared to increase $\mathrm{UV}, \mathrm{UNaV}_{\mathrm{V}}$, $\mathrm{U}_{\mathrm{cAMPV}}$ and $\mathrm{U}_{\mathrm{cGMPV}} \mathrm{V}$, whereas these variables did not change significantly after switching to hANP monotherapy. This suggests that the observed renal effects of AM+hANP therapy may be mainly due to a hANP effect. Many studies have demonstrated that AM has renal vasodilatory, natriuretic and diuretic actions? ${ }^{2}$ We also reported previously that intravenous infusion of AM $\left(0.05 \mu \mathrm{g} \cdot \mathrm{kg}^{-1} \cdot \mathrm{min}^{-1}\right)$ increases GFR, UV and $\mathrm{UNaV}$ in rat and human heart failure! $10,11,16$ The possible reasons why an obvious renal effect from AM was not observed may be due to: (1) the low dose of AM $\left(0.02 \mu \mathrm{g} \cdot \mathrm{kg}^{-1} \cdot \mathrm{min}^{-1}\right) \mathrm{used}$; and (2) the severe intensity of heart failure in the present study.

Thus, the present study indicated that the combination of AM and hANP would be good for: (1) potential strong preload and afterload reduction; (2) HR stability through mutual suppression of an AM-induced-HR-increase with hANP and a hANP-induced-HR-decrease with AM; and (3) neurohumoral changes.

We have the following limitations of the present study: (1) the study had a small number of cases and did not have enough subjects to detect a statistical difference in all timepoints between baseline values and AM+hANP therapy with regard to hemodynamic parameters; (2) a fixed dose of AM was used regardless of the severity of heart failure, thus the response to the AM+hANP therapy might be blunted in severe ADHF patients; (3) subjects with different heart failure etiologies were included in the present study; and (4) patients with relatively different severities of heart failure were included. Despite these heterogeneities, AM+hANP therapy could show some beneficial hemodynamic and hormonal effects in ADHF.

In summary, we evaluated the effect of AM+hANP therapy in a small pilot study of patients with ADHF. The administration of AM+hANP was associated with a reduction in SVR, PAR, PCWP, mPA, MAP, aldosterone, BNP and d-ROM, and with an increase in CI, UV, UNaV, UcAMPV and $\mathrm{U}_{\mathrm{cGMPV}}$. These data are preliminary and require confirmation in a larger clinical trial.

\section{Acknowledgments}

This work was supported in part by Scientific Research Grants-in-Aid 14570692, 18590787, and 20590837 from the Ministry of Education, Culture, Sports, Science and Technology of Japan; the Science Research Promotion Fund from the Promotion and Mutual Aid Corporation for Private Schools of Japan; Research Grant for Cardiovascular Diseases 17A1 from the Ministry of Health, Labour and Welfare of Japan; and the Seki
Minato Prize. We thank Ms. Keiko Ishikawa, Ms. Masako Minato, Ms. Kyoko Tabei and Ms. Machiko Sakata for technical assistance. We also thank Toshiyasu Iwase and Chiaki Koshikawa for preparing the adrenomedullin injection.

\section{References}

1. Kitamura K, Kangawa K, Kawamoto M, Ichiki Y, Nakamura S, Matsuo H, Eto T. Adrenomedullin: A novel hypotensive peptide isolated from human pheochromocytoma. Biochem Biophys Res Commun 1993; 192: 553-560.

2. Nishikimi T. Adrenomedullin in the kidney-renal physiological and pathophysiological roles. Curr Med Chem 2007; 14: 1689-1699.

3. Nishikimi T, Matsuoka H. Cardiac adrenomedullin: Its role in cardiac hypertrophy and heart failure. Curr Med Chem Cardiovasc Hematol Agents 2005; 3: 231-242.

4. Nishikimi T, Saito Y, Kitamura K, Ishimitsu T, Eto T, Kangawa K, et al. Increased plasma levels of adrenomedullin in patients with heart failure. J Am Coll Cardiol 1995; 26: 1424-1431.

5. Kato J, Kobayashi K, Etoh T, Tanaka M, Kitamura K, Imamura T, et al. Plasma adrenomedullin concentration in patients with heart failure. J Clin Endocrinol Metab 1996; 81: 180-183.

6. Nishikimi T, Horio T, Sasaki T, Yoshihara F, Takishita S, Miyata A, et al. Cardiac production and secretion of adrenomedullin are increased in heart failure. Hypertension 1997; 30: 1369-1375.

7. Nagaya N, Nishikimi T, Horio T, Yoshihara F, Kanazawa A, Matsuo $\mathrm{H}$, et al. Cardiovascular and renal effects of adrenomedullin in rats with heart failure. Am J Physiol 1999; 276: R213-R218.

8. Meeran K, O'Shea D, Upton PD, Small CJ, Ghatei MA, Byfield PH, et al. Circulating adrenomedullin does not regulate systemic blood pressure but increases plasma prolactin after intravenous infusion in humans: A pharmacokinetic study. J Clin Endocrinol Metab 1997; 82: $95-100$

9. Lainchbury JG, Nicholls MG, Espiner EA, Yandle TG, Lewis LK, Richards AM. Bioactivity and interactions of adrenomedullin and brain natriuretic peptide in patients with heart failure. Hypertension 1999; 34: 70-75.

10. Nagaya N, Satoh T, Nishikimi T, Uematsu M, Furuichi S, Sakamaki F, et al. Hemodynamic, renal, and hormonal effects of adrenomedullin infusion in patients with congestive heart failure. Circulation 2000; 101: $498-503$

11. Oya H, Nagaya N, Furuichi S, Nishikimi T, Ueno K, Nakanishi N, et al. Comparison of intravenous adrenomedullin with atrial natriuretic peptide in patients with congestive heart failure. Am J Cardiol 2000; 86: $94-98$.

12. Nishikimi T, Yoshihara F, Horinaka S, Kobayashi N, Mori Y, Tadokoro K, et al. Chronic administration of adrenomedullin attenuates transition from left ventricular hypertrophy to heart failure in rats. Hypertension 2003; 42: 1034-1041.

13. Ishizaka $Y$, Ishizaka $Y$, Tanaka M, Kitamura K, Kangawa K, Minamino N, et al. Adrenomedullin stimulates cyclic AMP formation in rat vascular smooth muscle cells. Biochem Biophys Res Commun 1994; 200: 642-646.

14. Hayakawa H, Hirata Y, Kakoki M, Suzuki Y, Nishimatsu H, Nagata $\mathrm{D}$, et al. Role of nitric oxide-cGMP pathway in adrenomedullininduced vasodilation in the rat. Hypertension 1999; 33: 689-693.

15. Nakamura M, Yoshida H, Makita S, Arakawa N, Niinuma H, Hiramori $\mathrm{K}$. Potent and long-lasting vasodilatory effects of adrenomedullin in humans: Comparisons between normal subjects and patients with chronic heart failure. Circulation 1997; 95: 1214-1221.

16. Nagaya $N$, Nishikimi $T$, Uematsu $M$, Satoh $T$, Oya $H$, Kyotani $S$, et al. Haemodynamic and hormonal effects of adrenomedullin in patients with pulmonary hypertension. Heart 2000; 84: 653-658.

17. Abramson BL, Ando S, Notarius CF, Rongen GA, Floras JS. Effect of atrial natriuretic peptide on muscle sympathetic activity and its reflex control in human heart failure. Circulation 1999; 99: 18101815 .

18. Szokodi I, Kinnunen P, Tavi P, Weckström M, Tóth M, Ruskoaho H. Evidence for cAMP-independent mechanisms mediating the effects of adrenomedullin, a new inotropic peptide. Circulation 1998; 97: $1062-1070$.

19. Nagaya N, Goto Y, Satoh T, Sumida H, Kojima S, Miyatake K, et al. Intravenous adrenomedullin in myocardial function and energy metabolism in patients after myocardial infarction. $J$ Cardiovasc Pharmacol 2002; 39: 754-760.

20. Yoshimura M, Yasue H, Tanaka H, Kikuta K, Sumida H, Kato H, et al. Responses of plasma concentrations of A type natriuretic peptide and $B$ type natriuretic peptide to alacepril, an angiotensin-converting enzyme inhibitor, in patients with congestive heart failure. $\mathrm{Br}$ Heart $J$ 1994; 72: 528-533. 
21. Petrie MC, Hillier C, Morton JJ, McMurray JJ. Adrenomedullin selectively inhibits angiotensin II-induced aldosterone secretion in humans. J Hypertens 2000; 18: $61-64$.

22. Yamaguchi T, Baba K, Doi Y, Yano K, Kitamura K, Eto T. Inhibition of aldosterone production by adrenomedullin, a hypotensive peptide, in the rat. Hypertension 1996; 28: 308-314.

23. Liu J, Shimosawa T, Matsui H, Meng F, Supowit SC, DiPette DJ, et al. Adrenomedullin inhibits angiotensin II-induced oxidative stress via Csk-mediated inhibition of Src activity. Am J Physiol Heart Circ
Physiol 2007; 292: H1714-H1721.

24. Shono M, Yoshimura M, Nakayama M, Yamamuro M, Abe K, Suzuki $\mathrm{S}$, et al. Predominant effect of A-type natriuretic peptide on reduction of oxidative stress during the treatment of patients with heart failure. Circ J 2007; 71: 1040-1046.

25. Tanaka T, Tsutamoto T, Nishiyama K, Sakai H, Fujii M, Yamamoto $\mathrm{T}$, et al. Impact of oxidative stress on plasma adiponectin in patients with chronic heart failure. Circ J 2008; 72: 563-568. 